\title{
4. The choice of instrument for EU legislation: mapping the system of governance under MiFID II and MiFIR
}

\section{Magnus Strand ${ }^{1}$}

\subsection{INTRODUCTION}

Centralisation is a coat of many colours, and as is shown in this book it can be studied from many perspectives. Perhaps the broadest stripes in the pattern are those of the legal instruments governing the field at issue - in this case financial markets in the EU. This study focuses particularly on governance of EU markets in financial instruments under Directive 2014/65/EU of the European Parliament and of the Council of 15 May 2014 on markets in financial instruments [MiFID II], and Regulation (EU) No 600/2014 of the European Parliament and of the Council of 15 May 2014 on markets in financial instruments [MiFIR].

In this chapter the results of an empirical legal study are presented. It should be pointed out that legal studies are usually not empirical but hermeneutical. ${ }^{2}$ However, this is not a hermeneutical study of what one ought or ought not to do according to the texts comprising financial market law, and consequently not a study of the normative content of this law. Instead the study focuses on whether, and if so how, the governance of financial markets in the EU has been centralised at the EU level and more particularly whether, and if so to what extent, the choice of legal instrument is relevant to the degree of centralisation.

The study is thus focused on EU legislation and the governing effects of EU rulemaking, and more specifically on comparing the degree of centralisation achieved through the different forms of regulatory acts adopted by the EU. Consequently, the effects of international treaties and agreements on EU legislation are not covered here. In other words, the overarching subject of study is how the EU institutions have used their normative powers to adopt rules creating rights and obligations for the various agents involved in transactions in EU markets in financial instruments, together with the powers of and obligations 
on the agencies at both the EU and national levels which have been entrusted with the monitoring and enforcement of compliance with these rules.

In this context it should be further clarified that the results of the study are only formally valid for the instruments compared, which are those governing trade in financial instruments in the EU. It is nonetheless open for discussion whether some of the results have broader implications for EU rulemaking in general. In fact, this study was designed partly to test a method that may be more generally useful to analyse EU rulemaking, using rulemaking for the financial markets as a pilot study. The precise research question will now be presented.

\subsection{RESEARCH QUESTION AND MAIN RESULTS}

This study was designed to explore the level and character of EU centralisation resulting from MiFID II and MiFIR in order to investigate whether there is variation in the regulatory intensity (defined below) of the two instruments, whether or not any such variation seems to be attributable to the characters of regulations and directives, and finally to ascertain whether or not the results allow a hypothesis on the deliberations that prompt the EU legislator to put certain rules in a regulation and others in a directive. Essentially, it has been tested whether a case study on MiFID II and MiFIR will falsify the common preconceptions concerning the respective characters of regulations and directives, but the study also yields some interesting ancillary results, which will be discussed below.

The relevance of regulatory intensity to this study is related to a certain aspect of law that needs to be briefly explained. The legal point of departure with regard to businesses such as investment firms and the other actors involved in the financial markets is the freedom to conduct business enshrined in Article 16 of the Charter of Fundamental Rights of the European Union and the more specific fundamental freedoms of free movement in the internal market protected by the TFEU (those most relevant here being the right of establishment (Article 49 TFEU), the free movement of services (Article 56 TFEU) and the free movement of capital (Article 63 TFEU)). These rights and freedoms are subject to limitations by law, but as a general legal point of departure any absence of legal rules governing the exercise of them means that the actors are, in principle, free to conduct their businesses as they see fit. It follows that an introduction of new rules shifts power in these markets from the businesses involved to the rulemakers, which can be described as a centralisation of power by legislative pre-emption. Rulemaking can take place in various ways and traditionally does so in national parliaments. The object of this study is, however, rulemaking in the EU. If the rulemakers at issue are at the EU level, it means centralisation of power in the EU. Therefore, a higher 
level of regulatory intensity in principle means a higher level of EU governance through the legislative and non-legislative instruments employed and consequently a higher degree of centralisation. This legal point of departure has guided the design of this study.

On the basis of this study, it is concluded below that at a general level the choice of legislative instrument adopted by the EU legislator (a regulation or directive) did not in this case seem to have any significant impact on the level of centralisation achieved using the instrument. Instead, the rules in the instrument seem to address different agents. MiFIR mainly governs the EU levels of administration and MiFID II mainly governs the national levels of administration and the rights of and obligations on private parties. However, it is further demonstrated that the activities of national authorities are also governed through the adoption of non-legislative acts. With few exceptions, these are regulations. This means that powers conferred on EU institutions under MiFID II and MiFIR entail a possibility of pre-emption of Member State discretion, which can be described as at least potential centralisation. Moreover, the Commission has used this possibility extensively, adopting non-legislative acts constituting real centralisation. With regard to MiFID II and MiFIR, the overarching legislative acts, the common preconceptions concerning the respective characters of regulations and directives are not falsified, but the results suggest that the use of a directive to govern national administrations and private parties may conceal the fact that they are to a large extent governed through non-legislative acts in the form of regulations. This form of normative governance through non-legislative acts is perhaps the most conspicuous aspect of EU centralisation in the legal governance of financial markets found in this study.

Another legal factor deserving mention is that elements of legal uncertainty and fragmentation are inevitable in any new set of legislation. The system of governance adopted for trade in financial markets is no exception. Over time, at least some of these elements will be addressed by the European Court of Justice in the context of preliminary rulings under Article 267 TFEU. Through such rulings, legal uncertainties can be straightened out and gaps filled, gradually forming a more coherent set of rules. This process serves to align interpretations of the applicable legal acts in order to achieve uniformity in their application. Of course, the process also adds further elements of centralisation to the legislation thus addressed.

As this summary has highlighted, there are a number of aspects of EU law that need to be explained in order to allow the reader to understand this study. Therefore, before presenting the research question and the method used in more detail, it is necessary to provide some background information on the EU legal system. The focus will be on EU rulemaking. 


\subsection{BACKGROUND: LEGAL ACTS OF THE EU}

\subsubsection{The Classes of Legal Acts under Art 288 TFEU}

In the EU, legislation intended to harmonise the laws of all Member States can be enacted by the EU institutions in accordance with rules and procedures laid down in the EU Treaties. Most of the details are included in the TFEU. Article 288 TFEU specifies that legal acts of the EU can be regulations, directives, decisions, recommendations or opinions. For the purpose of harmonising the regulatory system controlling financial markets in the EU, the legal acts mainly adopted are regulations and directives. These are the two most common types or classes of legal acts used by the EU legislator to adopt regulatory measures of general application. With regard to regulations and directives, Article 288 TFEU further specifies:

A regulation shall have general application. It shall be binding in its entirety and directly applicable in all Member States.

A directive shall be binding, as to the result to be achieved, upon each Member State to which it is addressed, but shall leave to the national authorities the choice of form and methods.

It does not follow from this description that directives are generally valid in all Member States, and historically not all directives have been designed to be binding on all Member States. It has, however, become highly unusual for a directive to not be addressed to all the Member States of the EU. Consequently, the normative content of directives (in other words, 'the result to be achieved') is generally intended to be transposed into the national legal systems of all the Member States.

The EU legislator has generally had a preference for regulations over directives (Bergström 2005: 12), and in the last 20 years this preference has spread in an unprecedented way into legislation concerning the internal market (SOU 2009: 71, 323). It is commonly accepted that this is because, as was explained in the introductory chapter of this book, EU rules are implemented differently in Member States depending on their specific national economic, political, institutional, legal and social conditions. Therefore, the outcome in terms of the regulatory structure and policy substance in the various Member States is not necessarily uniform (e.g. H1.1). This generally applies to directives more than to regulations. By contrast, regulations typically take less time to become legally effective (as there is no need to offer Member States a transposition period to convert their rules into national law), are applied directly and so are less vulnerable to national transposition errors, and (as a consequence) do not to the same extent as directives necessitate monitoring and enforcement of their 
implementation in the Member States by the Commission. A sense of urgency, such as that driving the post-crisis wave of legislation in the area of financial markets, is liable to increase the incentives for the Commission to suggest a regulation and also to lessen resistance in the Council against the choice of a regulation over a directive (de Larosière 2009: 29). This would suggest that urgency may be a factor driving centralisation. It will, however, be explained below that it may be an over-simplification to suggest that regulations per se lead to more centralisation than directives. In this regard it is interesting to notice that for the purpose of regulating trade in financial instruments the EU legislator has opted for the combination of a regulation and a directive. This has inspired the research questions below, which aim to compare and test the degree of centralisation resulting from use of these legal instruments, and to achieve a fuller understanding of EU rulemaking by differentiating between the legal actors and subject matters addressed by the rules in the legal instruments. For instance, was the choice of adding a regulation primarily triggered by a wish to govern the conduct of investment firms and other private actors in the financial markets more closely or instead by a need to regulate institutional interaction between national authorities on the one hand and EU institutions and agencies on the other?

Concerning the other classes of legal acts, it should first be noted that, in contrast to regulations and directives, decisions are usually aimed at specific addressees and are only binding on them. There are nevertheless, and interestingly, decisions of general application, some of which are part of the regulatory system controlling financial markets in the EU. Recommendations and opinions are so-called 'soft-law' instruments that are not generally binding, and they will therefore not be discussed further here. ${ }^{3}$

\subsubsection{The Distinction between Legislative and Non-legislative Acts}

The legal instruments adopted by the EU legislator can not only be sub-divided into the five classes of legal acts described in Article 288 TFEU. Another and arguably equally important distinction follows from subsequent TFEU Articles: that between legislative and non-legislative acts.

The latter term is somewhat counter-intuitive as non-legislative acts are indeed binding legal acts that are enacted as regulations, directives or any other class of legal act described under Article 288 TFEU. The concepts of 'legislative acts' and 'non-legislative acts' are not intended to indicate any difference in the binding nature of the instruments within these categories. Instead, they indicate the legislative procedure which is used by the EU legislator to adopt the legal acts in question. In this regard, Article 289(3) TFEU specifies that "[1] egal acts adopted by legislative procedure shall constitute legislative acts." 
By contrast, legal acts adopted in any other way than by legislative procedure constitute non-legislative acts.

By 'legislative procedure' Article 289 TFEU means the ordinary legislative procedure (see Articles 289(1) and 294 TFEU) and the various special legislative procedures provided for in the EU Treaties to accommodate particular policy areas (see Articles 289(2) and, for example, 86(1) TFEU). With regard to the regulatory system applicable to markets in financial instruments in the EU, there are at present two central instruments that have been adopted by legislative procedure and that are consequently legislative acts: MiFID II and MiFIR.

The TFEU explicitly outlines two sub-categories of non-legislative acts: delegated acts and implementing acts. Under Article 290 TFEU, legislative acts may include provisions on a delegation of power to the Commission to adopt non-legislative acts of general application in order to supplement or amend "certain non-essential elements of the legislative act". Such non-legislative acts adopted by the Commission are delegated acts, and they are subject to special conditions laid down in the legislative acts delegating power to the Commission. Similarly, under Article 291 TFEU, the Commission (or exceptionally the Council) is empowered to adopt non-legislative acts in situations where "uniform conditions for implementing legally binding Union acts are needed". These non-legislative acts are implementing acts and they are subject to control by the Member States under Regulation (EU) No. 182/2011 of the European Parliament and of the Council of 16 February 2011 laying down the rules and general principles concerning mechanisms for control by Member States of the Commission's exercise of implementing powers.

Member States, however, have much less control over non-legislative acts than legislative acts, notwithstanding the conditions for delegation and the control mechanisms in Regulation (EU) No. 182/2011. As non-legislative acts need to pass neither through the European Parliament or the Council, and nor to pass through the procedure for national parliamentary review of new EU acts under Protocol (No 2) on the Application of the Principles of Subsidiarity and Proportionality, there is an absence of strong veto players in the rulemaking process (H2). This is liable to drive centralisation by Commission rulemaking, as the Commission will be tempted to increase its institutional power in order to more effectively control the financial markets.

As will be demonstrated below, many provisions in MiFID II and MiFIR include delegations of power to the Commission to adopt non-legislative acts, and these powers have been used to adopt more than 50 non-legislative acts. The adoption of such non-legislative acts by the Commission inevitably involves what in this book we have called 'intentional uploading of formal legislative rule-making and rule supervision to the supranational level'. In order to decide whether this includes real centralisation we would also need 
to analyse the rules in the non-legislative acts to ascertain whether they are prescriptive in detail (H4.1 and H4.2). While it can be hypothesised that elements in these non-legislative acts adopted by the Commission do meet the definition, it is beyond the scope of this contribution to analyse the content of rules in non-legislative acts. The focus here is instead on the rules in MiFID II and MiFIR themselves. Nonetheless, delegations of powers to the Commission and its use of those powers are mapped.

\subsubsection{Non-legislative Acts Adopted by EU Agencies}

Legal instruments are not only adopted by EU institutions, however, but also by bodies, offices and agencies of the EU (EU agencies) when they have been empowered to do so by delegation from an EU institution. As will be indicated below, this has occurred under MiFID II and MiFIR, as certain acts have been adopted by the European Securities and Markets Authority (ESMA). Consequently, the ESMA and other EU agencies can have a number of capacities in the governance of financial markets in the EU, including normative capacity, making them a kind of 'regulatory intermediaries' (Abbott et al. 2017). Indeed, among the European supervisory agencies involved in the governance of the financial markets in the EU, the ESMA is the one holding the most comprehensive set of powers, both to directly monitor actors in these markets and to take action to sanction non-compliance with EU law.

The delegation of normative powers by the EU institutions to specialised agencies is not new but dates back to the European Coal and Steel Community. In its classic case law on this matter, including case 9/56 Meroni, EU:C:1958:7 and case 98/80 Romano, EU:C:1981:4, the European Court of Justice has adopted quite stringent conditions for the delegation of normative powers to EU agencies. The extent and the circumstances under which EU agencies should be able to adopt binding norms - what we would now call non-legislative acts - have continued to be a matter of some legal debate (Lenaerts 1993; Schammo 2011; van Cleynenbreugel 2014; Bergström 2015; Chamon 2016: 185-199). Recent case law, such as case C-270/12 UKv EP and Council (Short selling), EU:C:2014:18, suggests that the Court of Justice has relaxed its previous approach, or at least that it has substituted the conditions for the delegation of powers in its early case law with new conditions and will tolerate the delegation of powers to EU agencies, including the power to adopt non-legislative acts of general application and non-legislative acts that are addressed to, and legally binding on, specific individuals (van Cleynenbreugel 2014; Bergström 2015). The conditions set out in the Short selling case are essentially that: 
1. There is a legal basis for EU legislation on the matter at issue;

2. The delegation of powers is precisely delineated and amenable to judicial review; and

3. The delegation of powers is confined to an area which requires the deployment of specific expertise. ${ }^{4}$

Arguably, these conditions amount to an expansion of the possibilities for EU institutions to delegate supranational normative power to EU agencies (van Cleynenbreugel 2014: 88). It has therefore been submitted that the new approach of the Court of Justice risks tilting the institutional balance of powers within the EU unless the institutions find a way to arrange for mutual political supervision of their delegations of power (Bergström 2015: 241-242; Chamon 2016: 227 and 246-248).

Regardless of whether this will come to pass, it should be observed for our present purposes that the new approach of the Court of Justice has further enabled the ongoing centralisation of EU rulemaking. Non-legislative acts inevitably involve what we call 'intentional uploading of formal legislative rule-making and rule supervision to the supranational level'. In order to decide whether this includes real centralisation we would also need to analyse the rules in the non-legislative acts to ascertain whether they are prescriptive in detail (H4.1 and H4.2). As with non-legislative acts adopted by the Commission, it can be hypothesised that elements of these non-legislative acts adopted by the ESMA will include centralisation. Nonetheless their normative content will not be analysed here, as the focus is on the rules in MiFID II and MiFIR.

\subsubsection{Overview: Non-legislative Acts Adopted under MiFID II and MiFIR}

Among the legal acts applicable to markets in financial instruments in the EU, MiFID II (a directive) and MiFIR (a regulation) are both legislative acts and were adopted by the EU legislator under the ordinary legislative procedure. However, these two legislative acts are (at the time of writing and excluding instruments not in force and instruments amending other instruments) complemented by no less than 54 non-legislative acts, 52 of which have been adopted by the Commission. With a few exceptions, these non-legislative acts are regulations and the majority are delegated acts (see Table 4.1).

As is apparent from this simple table, the possibility of delegating normative powers to the ESMA has not been used particularly often under MiFID II and MiFIR. Instead, the non-legislative acts in this field have with only a few exceptions been adopted by the Commission. It is further apparent that the legislative instrument of preference is the regulation, an instrument which, under Article 288 TFEU, is of general application and which is binding in its 


\section{Table 4.1 Non-legislative acts adopted under MiFID II and MiFIR}

\begin{tabular}{llll}
\hline Type of non-legislative act & $\begin{array}{l}\text { Total no. of acts of } \\
\text { this type }\end{array}$ & Acts adopted by & Classes of legal acts \\
\hline Delegated acts & 40 & Commission: 40 & $\begin{array}{l}\text { Regulations: } 39 \\
\text { Directives: } 1\end{array}$ \\
& 12 & Commission: 12 & $\begin{array}{l}\text { Regulations: } 11 \\
\text { Decisions: } 1\end{array}$ \\
Implementing acts & 2 & ESMA: 2 & Decisions: 2 \\
$\begin{array}{l}\text { Other acts based on delegation of } \\
\text { normative powers }\end{array}$ & 2 & & \\
\hline
\end{tabular}

entirety and directly applicable in all Member States, even where the power to adopt non-legislative acts has been conferred on the Commission by MiFID II, which is a directive. Indeed, the Commission has adopted 50 regulations under MiFID II and MiFIR but only one directive (and one decision). By contrast, under the previous regime, that is under the legislative act Directive 2004/39/ EC of the European Parliament and of the Council of 21 April 2004 on markets in financial instruments (MiFID I, not accompanied by any regulation adopted as a legislative act), which was in force from 30 April 2004 to 2 January 2018, the Commission only adopted a total of four non-legislative acts.

However, the observation that most of these non-legislative acts have been adopted by the Commission risks concealing a central trait shared by most of the non-legislative acts adopted under MiFID II and MiFIR, namely that they have been drafted by the ESMA for adoption by the Commission under the procedure for so-called technical standards. Under Regulation (EU) No 1095/2010 of the European Parliament and of the Council of 24 November 2010 establishing a European Supervisory Authority (ESMA), power is conferred on the ESMA to draft technical standards in the form of implementing (implementing technical standards (ITS), Article 15) or delegated acts (regulatory technical standards (RTS), Articles 10-14). The latter form is the more common under MiFID II and is the only one used under MiFIR. Among the non-legislative acts adopted by the Commission under MiFID II and MiFIR, only two regulations, one directive and one decision are neither RTS nor ITS. Of course, the decisions adopted by the ESMA under MiFID II and MiFIR are neither RTS nor ITS. In essence, this means that the ESMA assists the Commission in joint efforts to effectively control the financial markets. This is likely to further reinforce the impetus towards centralisation.

Under Articles 16(12) and 24 of MiFID II, the delegated directive at issue is designed to "specify the concrete organizational requirements (...) to be imposed on investment firms" and to "ensure that investment firms comply" with certain general principles related to information to clients. Just like the regulations, the directive was drafted in close cooperation with the ESMA, 
which, as is stated in the preamble (recital 32) of the delegated directive, "has been consulted for technical advice".

The decisions adopted have two distinctive characters. The first category of decisions is where the Commission or the ESMA acts under a specific delegation, for instance to pronounce that trading venues in a certain third country under supervision are to be considered equivalent to those in the EU, or that trade in a certain class of financial instrument is temporarily restricted. Decisions belonging to this first category are published in the Official Journal of the EU. The second category consists of decisions adopted by the ESMA board of directors delegating powers to the ESMA Chair in situations where a large number of decisions of a technical nature must be taken and it would be an administrative burden for the board of directors to do it themselves. Such decisions are not published in the Official Journal of the EU but only on the ESMA website.

\subsection{THE PRESENT RESEARCH INTEREST}

The study presented in this chapter is focused on the distinctive features of regulations and directives in an attempt to ascertain an indication of the extent to which the choice of legal instrument has an impact on the degree of centralisation. As described above, whereas directives specify a set of rules, and their purposes, to be transposed into national law by the Member States in a manner suitable to their national regulatory contexts, regulations are uniformly worded and cannot be reframed or altered by the Member States in any respect. In the light of these characteristics of regulations and directives it may seem a needless endeavour to distinguish whether MiFID II (the directive) or MiFIR (the regulation) includes a higher degree of centralisation. Since regulations have general application, are binding in their entirety and are directly applicable in all Member States, while directives are only binding in terms of the result to be achieved, it would seem to follow that a higher degree of centralisation should be achieved through regulations than through directives. ${ }^{5}$ This is certainly an important factor in the study, but there are reasons to question whether harmonisation of laws in the EU through a regulation necessarily comprises more centralisation than through a directive.

First, experience shows that the binding force of regulations will sometimes prompt the EU legislator to include various exceptions. Such exceptions can be made for specific Member States, exempting them from the scope of application of the regulation. For instance, Denmark, Ireland and the United Kingdom have opted to stay outside certain aspects of EU harmonisation within the area of freedom, security and justice, and consequently regulations in this area include declarations that these Member States are not included in the scope of the instrument. An example of this can be seen in Regulation (EU) No 
$1215 / 2012$ on jurisdiction and the recognition and enforcement of judgments in civil and commercial matters, recitals 40-41. Exceptions for the purpose of passing a regulation can also appear in the form of exceptions aimed at a specific issue that is sensitive for a certain Member State. For instance, Regulation (EU) 2016/679 on the protection of natural persons with regard to the processing of personal data (GDPR) includes exceptions designed to allow public access to official documents in Article 86 and recital 154. These were added as some Member States would block the Regulation without them (Bergström and Ruotsi 2018). This tendency to include exceptions, of whatever kind, in order to pass a draft regulation through the Council can give rise to what might be called a 'brittlefication' of regulations, in the sense that they may be binding and directly applicable but only at the cost of a diminished normative force, leaving them a more brittle type of instrument than directives. It may also be described as a form of regulatory fragmentation. Hypothetically, therefore, the choice of legal instrument is not determined bluntly by an endeavour to achieve uniform rules and a uniform application of them, but must be contextualised with a view to specifically understanding the political dynamics of the policy field at issue within and between the EU institutions that partake in the legislative procedure at issue.

Second, it has been demonstrated that an EU dimension to rulemaking can in itself have a negative impact on the legitimacy of new rules (Baldwin 1996). In European constitutional tradition, legal obligations on individuals imposed by the State (in contrast to legal obligations towards other individuals, governed by civil law) should be based on legislation passed by the national parliament. The most obvious example of this is perhaps the criminal law maxim nulla poena sine lege. This raises some questions on whether the choice of legal instrument, or more specifically the choice of the type of rules to allocate to MiFID II (a directive) or to MiFIR (a regulation) includes considerations of legitimacy in the European constitutional tradition. The EU legislator is fully constitutionally capable under Article 288 TFEU to adopt regulations including not only rights but also obligations for individuals, and if regulations do this then those rights and obligations are directly applicable before national courts and agencies. By contrast, the legal contents of a directive must be transposed into national law by each Member State, usually by an act of its parliament, thus legitimising their regulatory content under the national constitution. Indeed, this author has a distinct sense that the EU legislator avoids including substantive legal obligations on individuals in regulations (proving this would entail an ambitious big data analysis) and it might bolster the legitimacy of new rules if EU legislation including more substantive legal obligations on private individuals (including commercial enterprises) is adopted in the form of directives. To reconnect again to the example of criminal law, one might notice that the EU has the competence to adopt regu- 
lations on the structure and work of the EU agencies Eurojust and EPPO under Articles 85 and 86 TFEU, while rules on the definition of criminal offences and sanctions are to be adopted in directives under Article 83 TFEU. It does not seem far-fetched therefore to suggest that the EU legislator, recognising the sensitivity of constitutional legitimacy connected to passing legislation with legal obligations on individuals, might prefer to do so through directives. A hypothetical consequence of these factors is that the EU legislator's choice of legal instrument depends not so much on the extent to which it wishes to centralise or harmonise rules and policymaking, but rather to whom the rules and policies at issue are aimed. These considerations have inspired the choice of research question addressed in this study.

\subsection{METHOD}

Against this background, the concept of 'regulatory intensity' is introduced, it being understood that the concept is neutral to whether the EU legislator has opted for a regulation or a directive (or, theoretically, any other form of act) as the instrument containing the rules at issue. By regulatory intensity is meant:

1. A binding character of rules in the application stage (at which point, as regards directives, the regulatory content of the directive should ideally be fully and faithfully transposed into national law with a binding effect matching the intentions of the EU legislator);

2. The level of regulatory detail in rules, including

a. the amount of detail in the binding text passed by the EU legislator;

b. the inclusion of further guiding details in the preamble to the binding text; and

c. a passing of non-legislative acts adding further detail to the binding text of the instrument on which the non-legislative act is based.

In an effort to estimate the regulatory intensity of the legal texts studied here, they have been scrutinised in order to determine the points listed in the definition above.

In order to obtain workable data, the texts have been processed as follows:

1. The rules in the texts have been coded into the following categories:

a. Legal obligations (i.e. where it is indicated that an authority or other person 'shall' do something, or other expressions to this effect);

b. Discretionary powers (i.e. where it is indicated that an authority 'may' do something, or other expressions to this effect); 
c. Substantive rights (i.e. where it is indicated that a private party a legal person such as a commercial enterprise - 'may' do something, or other expressions to this effect).

When measuring regulatory intensity, it is understood that legal obligations represent imperatives that are binding on the regulatory addressee, that is, on the entity upon which the legal obligation is imposed. Discretionary powers and substantive rights, by contrast, provide leeway for the regulatory addressees to act in accordance with their own interests.

It should be further noticed that many legal obligations on one party have a flipside in the form of a legal right for another. For instance, the duty for a competent authority to do something to the benefit of investment firms can be seen as constituting a right for investment firms that the task at issue is carried out with due diligence. The analysis, however, focuses exclusively on the immediate meaning of the wordings used in the rules analysed, consequently disregarding such implicit legal consequences.

2. The level of detail in the individual rules has been coded as 'low', 'medium' or 'high', where a low level indicates that there is only a short sentence, medium indicates a long sentence or a few sentences, and high indicates several or many sentences. To this end, rules that stretch over several paragraphs in the text, and ones in which the same type of imperative has been repeated to the same regulatory addressee within a paragraph, and combinations of these two, have been regarded as one single rule as long as the general character of the instructions in the legal text remains unchanged.

3. The occurrence of further guiding details in the preamble to the individual rules is coded only as occurring or not occurring, without scrutiny of the amount of detail in the individual preamble recitals. It is noticed that in one instance there is a cross-reference from the MiFIR preamble to a MiFID II rule, but this instance is ignored.

4. The occurrence of further guiding details in non-legislative acts has only been coded as occurring or as not occurring without scrutiny of the content of the rules in the non-legislative acts (such as the amount of detail). Non-legislative acts are identified by using the databases on the ESMA website ('Single rulebook') and EUR-Lex. Only non-legislative acts in force by 1 January 2020 have been included. Non-legislative acts amending or correcting other non-legislative acts have been omitted.

Some rules have been omitted from the study. The omitted rules are on definitions, on the scope of application of the instrument or of certain provisions in the instruments, on amendments or alterations in other instruments, and transitional provisions. 
Certain characteristics of EU legislation have also prompted reclassification of the person addressed by rules. Where provisions are phrased so as to be aimed at private parties (e.g. investment firms) they have only been listed if they appear in separate paragraphs. Where they appear in the context of a paragraph aimed at a Member State or competent authority, they have instead been seen as being included in the instructions for the Member State or competent authority to attain a specific objective. Conversely, in MiFID II, rules may be phrased so as to be aimed at the Member States but the instruction may be for the Member States to enact legal obligations on private parties. It has been assumed for the purposes of this study that the regulatory content of a directive has been fully and faithfully transposed into national laws with a binding effect matching the intentions of the EU legislator, and accordingly such rules in MiFIR II have been classified as legal obligations on the private parties at issue in order not to thwart the ability of the study to provide useful answers to the research questions asked.

Because of the relative simplicity of the intended analysis, no statistical tools have been used. Instead, the quantifications of regulatory intensity ascertained for MiFID II and MiFIR, as a whole and in relation to the regulatory addressees (i.e. a public or private entity, the behaviour of which a rule is intended to govern), have been straightforwardly compared.

\section{Table 4.2 Overview of rules in MiFID II and MiFIR}

\begin{tabular}{llllll}
\hline $\begin{array}{l}\text { Instrument } \\
\text { and sum } \\
\text { total of rules } \\
\text { analysed }\end{array}$ & $\begin{array}{l}\text { No. of rules } \\
\text { imposing legal } \\
\text { obligations, } \\
\text { percentage }\end{array}$ & $\begin{array}{l}\text { No. of rules } \\
\text { conferring } \\
\text { discretionary } \\
\text { powers, } \\
\text { percentage }\end{array}$ & $\begin{array}{l}\text { No. of rules } \\
\text { conferring } \\
\text { substantive } \\
\text { rights, } \\
\text { percentage }\end{array}$ & $\begin{array}{l}\text { No. of } \\
\text { non-legislative } \\
\text { acts based on } \\
\text { instrument }\end{array}$ & $\begin{array}{l}\text { po. of } \\
\text { preamble } \\
\text { recitals } \\
\text { offering } \\
\text { guidance }\end{array}$ \\
\hline $\begin{array}{l}\text { MiFID II, } \\
427 \text { rules }\end{array}$ & $305,71 \%$ & $109,26 \%$ & $13,3 \%$ & 34 & 97 \\
MiFIR, & $227,73 \%$ & $71,23 \%$ & $11,4 \%$ & 21 & 30 \\
309 rules & & & & & \\
\hline
\end{tabular}

\subsection{RESULTS}

\subsubsection{Observations at the General Level}

Table 4.2 is an overview of the results for the entire instruments. Percentages are rounded off to whole numbers. Note that there are two rules in MiFID II and six rules in MiFIR that stipulate joint responsibilities for actors, for example, the ESMA and competent authorities. For the purposes of this study 
it is necessary to code each of these rules as two separate rules aimed at the two respective regulatory addressees concerned.

This very general comparison of MiFID II and MiFIR reveals little or no significant differences between them. In other words, the two instruments seem to have very similar regulatory intensity. Their respective balances between rules stipulating legal obligations, discretionary powers and substantive rights are quite well matched. The number of non-legislative acts adopted on the basis of the respective instruments also seems proportionate to the number of rules in them, and the same goes for connections between non-legislative acts and the rules in the instruments (a total of 108 connections in MiFID II, and a total of 82 connections in MiFIR, which are data not listed in Table 4.2). Only the numbers of substantively guiding recitals in their preambles seems to differ in any tangible way, although, interestingly, if Table 4.2 had instead displayed the number of connections between recitals and rules (as Tables 4.3-4.8 below do) the difference would be reversed (258 connections in MiFID II but as many as 313 in MiFIR, which are data not listed in Table 4.2). However, this has been considered a random variation that cannot serve as the basis for any conclusions.

In Table 4.3, results are listed for MiFID II and MiFIR distinguished by reference to the level of detail in the rules analysed. All the percentages are of the sum total in the categories (cf. Table 4.2).

With regard to connections between non-legislative acts and rules, on the one hand, and preamble recitals and rules, on the other hand, note that many non-legislative acts and many preamble recitals are connected to more than one of the rules analysed. As a consequence, Table 4.3 does not divulge, for example, that connections may have differing characters. For instance, one rule with a high level of detail connected to 10 recitals will register equally as 10 rules with a low level of detail connected to one single preamble recital.

Table 4.3 further suggests that rules stipulating legal obligations and rules conferring substantive rights have higher regulatory intensity in MiFID II as compared to MiFIR, while on the contrary rules conferring discretionary powers have higher regulatory intensity in MiFIR as compared to MiFID II. This difference has been considered interesting, and it was therefore decided to distinguish further between regulatory addressees in order to ascertain whether the variation in regulatory intensity is in some way distributed between regulatory addressees.

As a first step in this endeavour, the data were re-grouped on the basis of classes of regulatory addressees, that is, eliminating the previous distinction. Table 4.4 therefore lists quantities of MiFID II and MiFIR rules distinguished by their regulatory addressees, that is, the type of entity upon which the rules 


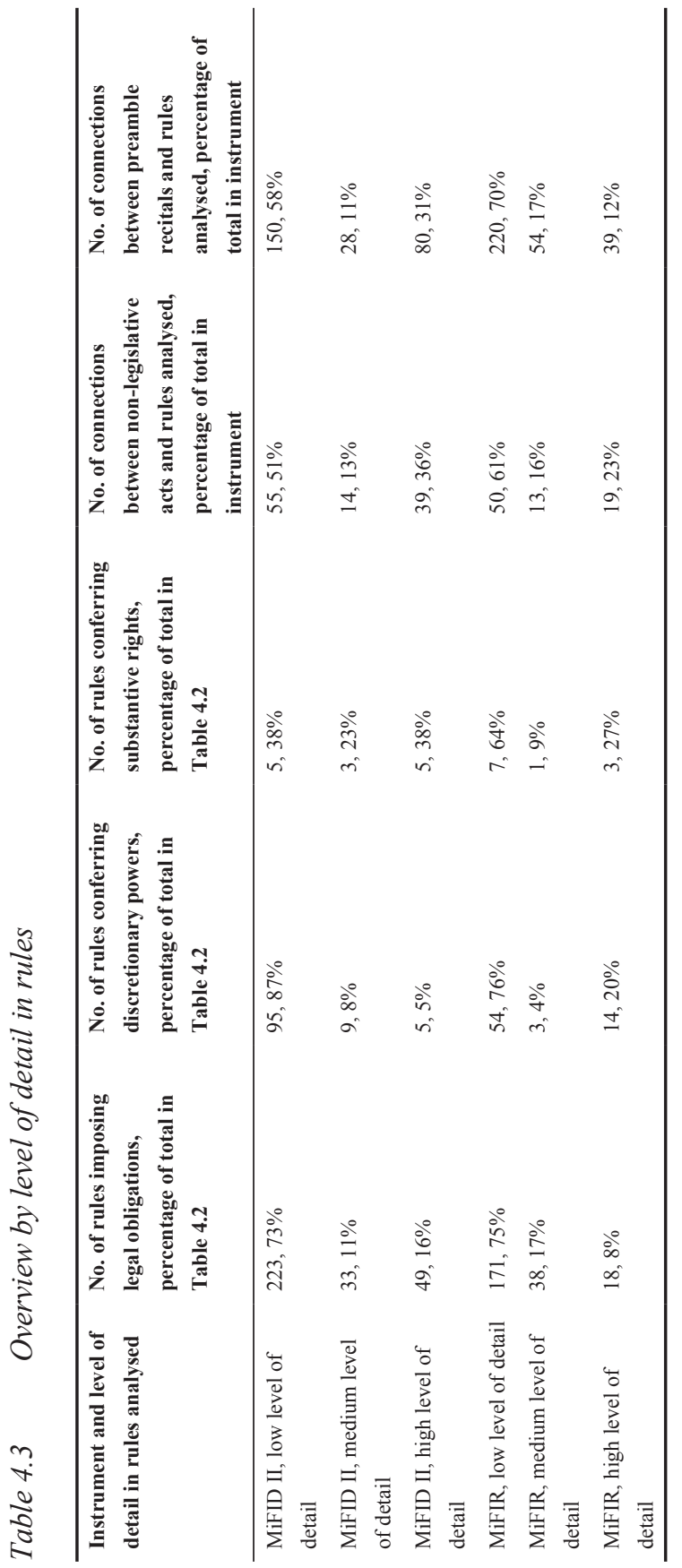


analysed impose an obligation or confer discretion/rights. The regulatory addressees named in the texts have been categorised as:

1. EU institutions;

2. EU agencies (e.g. the ESMA);

3. National legislators, governments and competent authorities (shorthand: MS actors);

4. Private parties (e.g. investment firms and market operators, shorthand: private parties).

All the percentages are of the sum total in the categories (cf. Table 4.2). N/A means not applicable.

With regard to rules imposing legal obligations, Table 4.4 suggests that EU institutions and agencies are mostly addressed through MiFIR rules, while Member State actors (e.g. national legislators and authorities) are more often addressed through MiFID II. Concerning discretionary powers and substantive rights, on the other hand, Table 4.4 suggests very few differences in the entities addressed by the rules in the respective instruments. It should, however, be noticed that the balance in the conferral of discretionary powers in both instruments is to the benefit of EU institutions, suggesting a clear element of centralisation.

By contrast, Table 4.4 includes interesting differences with regard to private parties. There is a comparatively larger proportion of rules conferring legal obligations on private parties in MiFIR than in MiFID II, although the reverse situation might have been expected under the constitutional view that legal obligations on individuals should be enacted by national parliaments (which would in the EU law context take place in the process of transposing a directive into national law). This has been seen as a further indication that the variation in regulatory intensity is in some way distributed between regulatory addressees, warranting further study of the details of this distribution. Finally, concerning discretionary powers and substantive rights, it is not possible to identify in Table 4.4 any significant differences between the entities addressed by the rules in the respective instruments.

Below, the rules listed in Table 4.4 are examined in more detail, mapping regulatory intensity in relation to the regulatory addressees.

\subsubsection{Observations at the Detailed Level}

Tables 4.5-4.8 allow comparison of the regulatory intensity in the two instruments according to the regulatory addressees. At this level, interesting differences appear. First, it is apparent that rules aimed at the EU institutions and EU agencies have a higher regulatory intensity in MiFIR than in MiFID II. Second, 


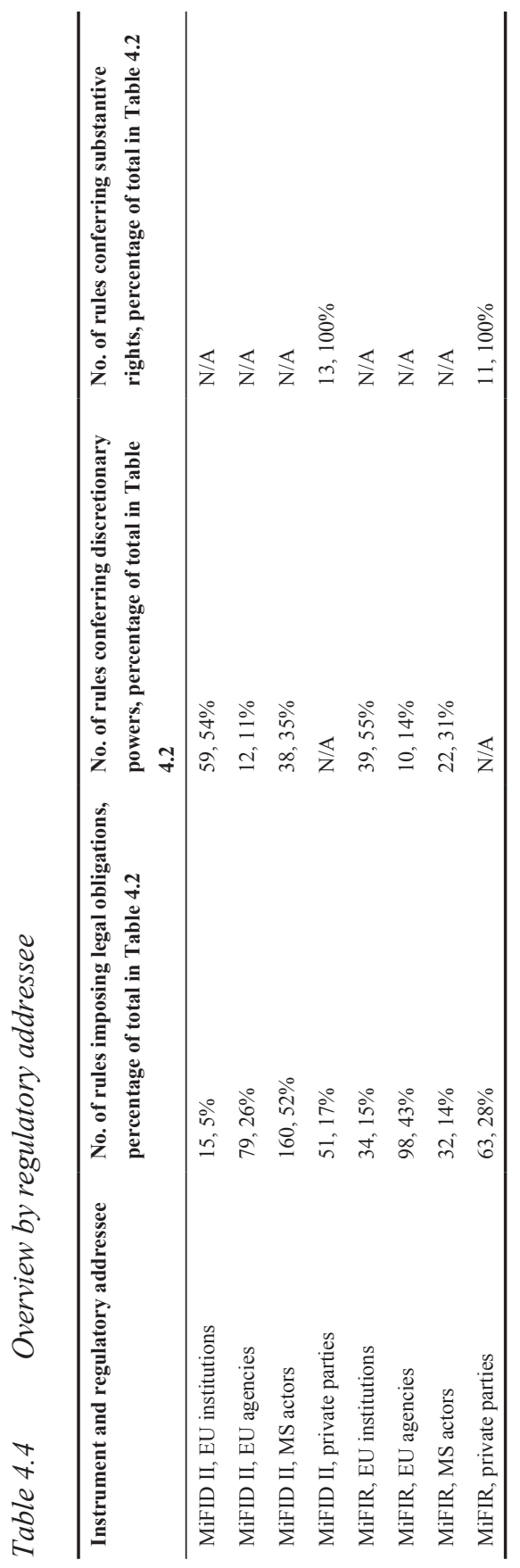


by contrast, it is apparent that rules aimed at Member State actors have higher regulatory intensity in MiFID II than in MiFIR. These tendencies are perhaps to be expected in view of the respective roles of regulations and directives. Third, however, with regard to the rights and obligations of private parties under the two instruments, it is much more difficult to see any obvious pattern.

\section{Comparing rules aimed at EU institutions}

Table 4.5 shows the rules aimed at EU institutions (i.e. the Commission, the Council and the European Parliament, although the last two only appear very scarcely), differentiating between rules creating legal obligations and discretionary powers, and differentiating by the level of regulatory intensity of the rules.

With regard to legal obligations conferred on EU institutions, it must be kept in mind that it further follows from Table 4.4 that EU institutions are more often addressed in MiFIR (34 rules creating legal obligations) than in MiFID II (15 rules to that effect). With this said, it also appears from Table 4.5 that a larger proportion of the MiFID II rules have a high regulatory intensity. The absolute numbers of rules with high regulatory intensity are nevertheless almost the same, five in MiFID II and four in MiFIR, and only the latter have any connection to the preamble, albeit only to one recital. Furthermore, MiFIR includes legal obligations on EU institutions with medium intensity which are also connected to preamble recitals, whereas MiFID II contains no rules with medium intensity.

Rules giving EU institutions discretionary powers are more common, the vast majority being rules with a low regulatory intensity. It was noticed in connection with Table 4.4 that the amount of conferral of discretionary powers to EU institutions suggests a clear element of centralisation. Most of these are short rules to the effect that the Commission has the power to adopt non-legislative acts drafted by the ESMA and/or other EU agencies. This will be discussed further below. Table 4.5 shows that there is a larger ratio of rules with high regulatory intensity in MiFIR than in MiFID II, but the absolute numbers are small and it is therefore difficult to make reliable comparisons.

Overall, Table 4.5 adds little to Table 4.4 but confirms that there are more rules stipulating legal obligations on EU institutions in MiFIR than there are in MiFID II. The regulatory intensity of the two instruments is difficult to compare but it is to be noted that only MiFIR contains legal obligations with medium regulatory intensity. Therefore, the level of regulatory intensity might, in the aggregate, be described as slightly higher in MiFIR than in MiFID II with regard to legal obligations on EU institutions. 


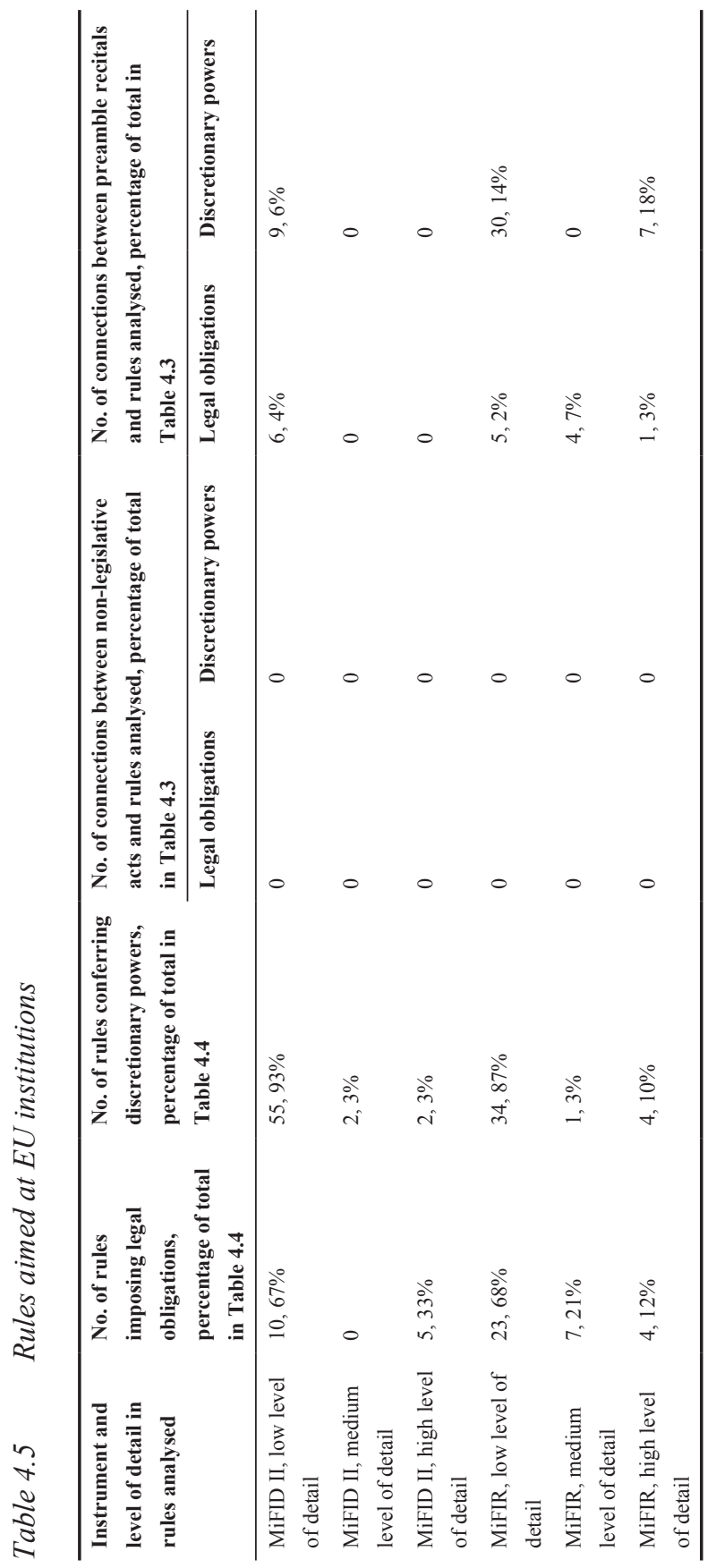




\section{Comparing rules aimed at $\mathbf{E U}$ agencies}

In Table 4.6 rules are assembled that are aimed at EU agencies (predominantly the ESMA, but also the European Banking Authority (EBA), the European Securities Committee and the Agency for the Cooperation of Energy Regulators), with differentiation between rules creating legal obligations and discretionary powers and differentiation by the level of regulatory intensity of the rules.

Going back to Table 4.4, it follows from that table that, as with EU institutions, the legal obligations on EU agencies have more often been enacted through MiFIR (98 rules creating legal obligations) than through MiFID II (74 rules). The difference is even clearer when we focus on the percentages in Table 4.4, where it was shown that as much as 43 per cent of the legal obligations stipulated in MiFIR are aimed at EU agencies. By contrast, legal obligations stipulated in MiFID II only aim at EU agencies in 26 per cent of the instances. Many of the legal obligations on EU agencies in both instruments consist in an instruction to draft non-legislative acts for adoption by the Commission. Other common duties include to interact with and, in various ways, to support national authorities in their monitoring activities. Comparing the regulatory intensity of the two instruments, it does not seem there is much difference but, as with EU institutions, MiFIR contains more legal obligations with medium regulatory intensity, and the rules have served as bases for more non-legislative acts. Consequently, it seems that the regulatory intensity in rules stipulating legal obligations on EU agencies is slightly higher in MiFIR than in MiFID II.

By contrast, there is a clear difference when we look at rules conferring discretionary powers on EU agencies. In this sample, there is a much larger proportion of rules with high regulatory intensity in MiFIR (four rules) than in MiFID II (one rule). Admittedly, the numbers are not large, but it should be further noted that there are four non-legislative acts adopted on the basis of MiFIR rules with high regulatory intensity while there are none based on MiFID II rules with high regulatory intensity. One example of such a rule is Articles 40 and 41 in MiFIR, under which the ESMA and the EBA are granted temporary intervention powers in the event that the agency needs to address "a significant investor protection concern or a threat to the orderly functioning and integrity of the financial markets or to the stability of the whole or part of the financial system in the Union", and the issue has not been and cannot be properly addressed otherwise. Another of the rules concerned, Article 45 , is similar in nature, while the last, Article 49, serves similar interests but concerns the activities of third-country firms specifically. It is very interesting in this context to notice that under Articles 40, 41 and 45, the Commission is given the power to adopt delegated acts specifying "criteria and factors to be taken into account" by the EU agencies in their assessment of whether they 


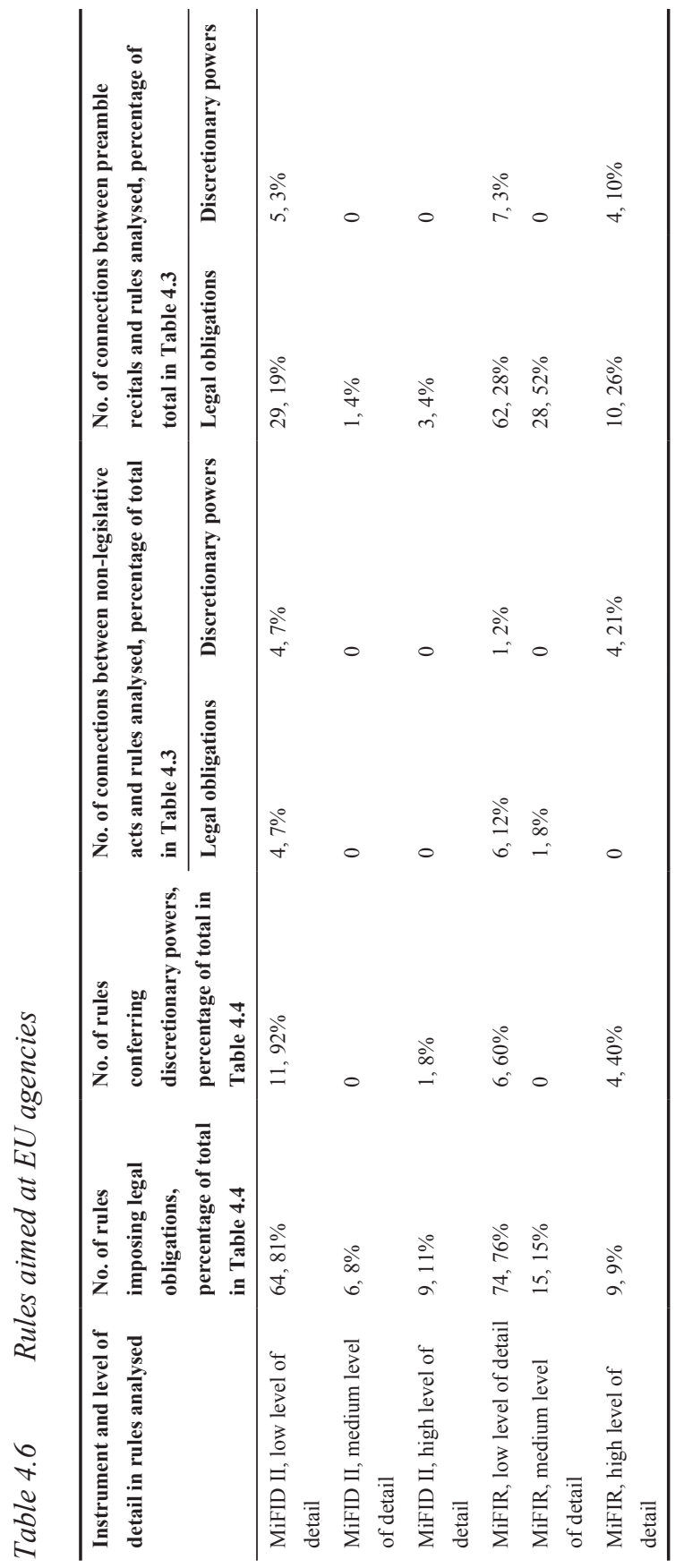


should proceed to use their temporary intervention powers (cf. the aforementioned Meroni case). The Commission has also done this: the criteria and factors at issue are laid down (for the purposes of all three Articles) in Commission Delegated Regulation (EU) 2017/567. Recitals 29-31 in the preamble to MiFIR are, moreover, relevant in this context. Evidently, quite some attention has been devoted to these issues by the EU legislator, seemingly in order to control the use of temporary intervention powers.

In sum, it follows from Tables 4.4 and 4.6 that there are more rules governing EU agencies in MiFIR than in MiFID II, suggesting again that at the EU level of the system of governance in the financial markets, MiFIR offers more centralisation than MiFID II. It was demonstrated through Table 4.6 that there is no significant difference in regulatory intensity between the two instruments as regards the legal obligations of EU agencies but that there is a significant difference concerning their discretionary powers. Analysis of the rules in question has allowed the hypothesis that the reason behind this difference is that the EU legislator has wished to control EU agencies' use of temporary intervention powers.

\section{Comparing rules aimed at Member State actors}

In Table 4.7 is displayed the design of rules aimed at one or another emanation of the Member States of the EU, commonly the authorities designated to monitor the financial markets but also Member State legislators and governments. All these regulatory addressees have been grouped together as 'Member state actors.' Rules creating legal obligations have been distinguished from rules conferring discretionary powers and the level of regulatory intensity of the rules has been introduced as a variable.

It was concluded from Table 4.4 that legal obligations on Member State actors are mostly stipulated in MiFID II, with such duties for Member States making up 52 per cent of the legal obligations listed in this instrument. Notably, this figure does not include legal obligations on private parties, constituting another 17 per cent of the rules in MiFID II, which are (or should be) listed in the instrument as obligations on the Member States to enact these obligations through national legislation or the like. In any event, the majority of legal obligations in MiFID II are aimed at Member State actors. In MiFIR, the reverse is true, as the legal obligations in the latter instrument are only aimed at Member State actors in 14 per cent of instances, which is the smallest proportion of legal obligations in that instrument. These differences coincide with expectations of the respective functions of regulations and directives.

Contemplating Table 4.7, and focusing first on rules conferring legal obligations on Member State actors, it seems that the regulatory intensity of these rules is equivalent in MiFID II and MiFIR. However, a startling difference appears if the focus is turned to the number of connections to non-legislative 


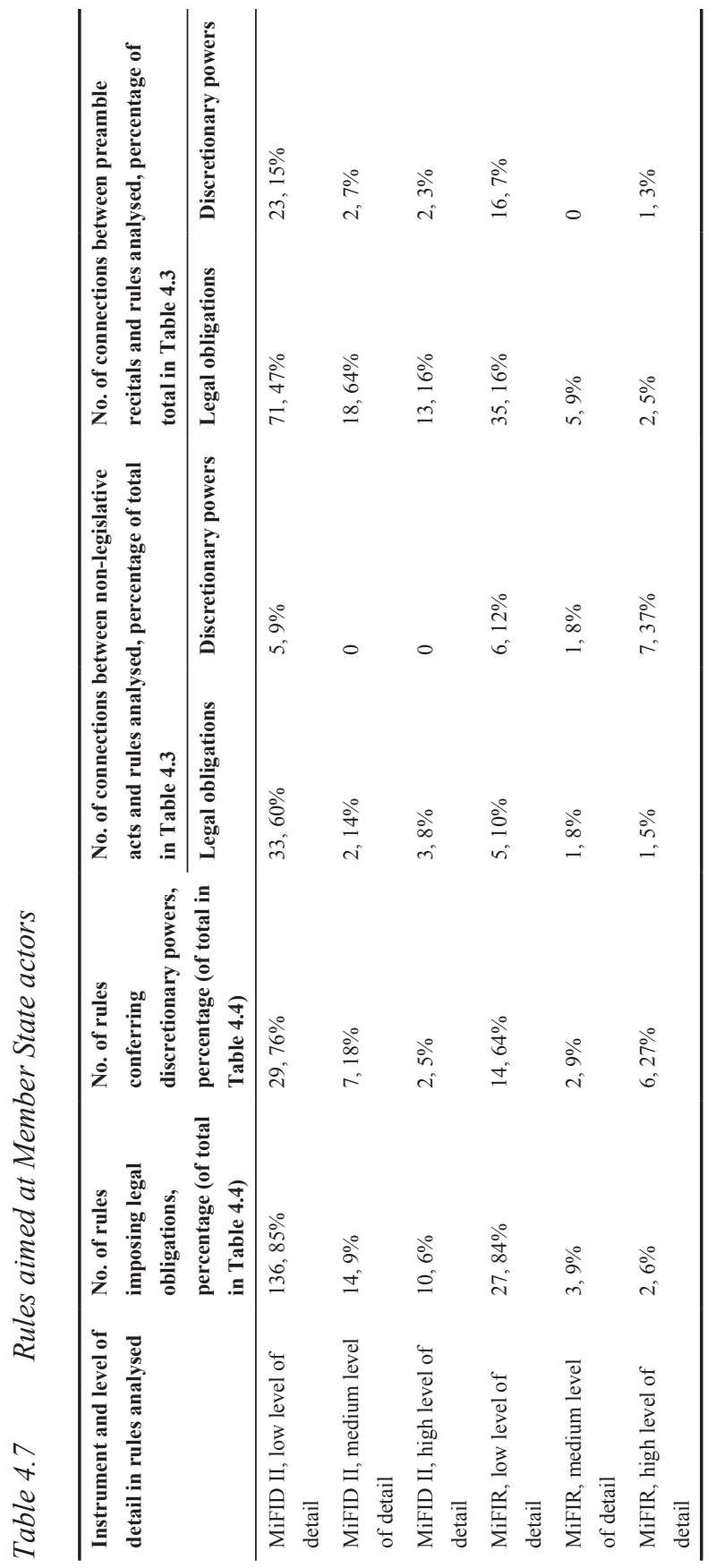


acts based on these rules and the number of connections with preamble recitals. In MiFID II, 60 per cent of the connections to non-legislative acts are in legal obligations with low regulatory intensity. Furthermore, 47 per cent of the connections to preamble recitals are in legal obligations with low regulatory intensity and, moreover, 64 per cent of the connections to preamble recitals are in legal obligations with medium regulatory intensity. No similar emphasis follows from the corresponding MiFIR samples. In rules with high regulatory intensity there are also more connections to both non-legislative acts and to preamble recitals in MiFID II rules than in MiFIR rules, but the difference is less conspicuous. The data do not allow any in-depth analysis of the rules concerned but only of the general tendency, which suggests that legal obligations on Member States laid down in MiFID II with low regulatory intensity are to a comparatively very high degree elaborated in preamble recitals and in non-legislative acts. There is a much lesser tendency to do this in MiFIR. As for the reason why this is so, it is difficult to put forward any hypothesis related to the substantive content of the rules; the picture that emerges from the data is fragmented. It may, however, be worth pointing out that there are 11 non-legislative acts adopted under MiFID II laying down implementing technical standards, but none under MiFIR. If this is taken as an indication, it seems there is a greater degree of hidden centralisation taking place under MiFID II than under MiFIR in the form of non-legislative acts partially pre-empting the margin of discretion for national authorities. This hypothesis warrants further study, for which there is no room here.

Second, with regard to the rules giving Member State actors discretionary powers, Table 4.7 indicates that it is more common for rules in MiFIR to have high regulatory intensity than it is in MiFID II. There are also significantly more connections to non-legislative acts in rules on discretionary powers of Member State actors in MiFIR (14 acts) than in MiFID II (five acts). The rules at issue give power to national authorities to, for example, grant authorisation to private parties and to waive or suspend some of their obligations. It was noted in the course of the study that most if not all such powers for national authorities are coupled with a power for the ESMA and/or the Commission to circumscribe the margin of appreciation for national authorities by adopting non-legislative acts specifying how that power can be used. Consequently, the reason behind the high regulatory intensity is hypothetically the same, in essence, as in the MiFID II rules on legal obligations on Member State actors. This does not seem to have been necessary in the few corresponding MiFID II rules.

To summarise, there seems to be a tendency to control the activities of national authorities through non-legislative acts and through preamble recitals. In MiFID II, the tendency is obvious in relation to legal obligations on Member State actors, while in MiFIR it is comparatively stronger in relation 
to discretionary powers for Member State actors. The data do not lend themselves to clear conclusions on the reasons behind these tendencies, but it can be hypothesised that the EU legislator wished to create possibilities for the EU institutions and agencies to partially pre-empt the margins of discretion that national authorities enjoy under the frameworks of MiFID II and MiFIR. This opportunity also seems to have been used, and it would be worth studying how this governs work in the national authorities concerned.

\section{Comparing rules aimed at private parties}

Table 4.4 would not serve as the basis for any conclusions in relation to rules conferring substantive rights on private parties. As regards legal obligations on private parties, it was mentioned above that the EU legislator may plausibly avoid creating legal obligations on private individuals in regulations, even though under Article 288 TFEU regulations are fully constitutionally capable of generating not only rights but also obligations on individuals. It would seem from Table 4.8 that this hypothesis is falsified by MiFIR, which on the contrary includes more legal obligations aimed at private parties, and a larger ratio of such rules, than MiFID II does.

The details of legal obligations conferred (or to be conferred) on private parties under the two instruments reveal, however, that the legal obligations in MiFIR generally have low regulatory intensity whereas 49 per cent of those in MiFID II have high regulatory intensity. Scrutinising the data, it seems that most of the legal obligations on private parties in MiFIR (but not all) are instructions to provide national and European authorities with information, or to make information publicly available. By contrast, most (but not all) legal obligations on private parties under MiFID II are substantive obligations that are to be enacted by the Member State legislators. This is further evident in the observation that the legal obligations under MiFIR are more often connected to regulatory or implementing standards in non-legislative acts (laying down details for the communication of information) than the corresponding rules in MiFID II. Consequently, it is concluded that the pattern in Table 4.4 can, to a large extent, be explained by reference to the general character of the legal obligations at issue. Indeed, in line with this hypothesis, substantive legal obligations of private parties are generally found in MiFID II while the legal obligations under MiFIR are generally procedural in character. It would be interesting to follow up this result by mapping the extent to which the two instruments provide for legal consequences in the event of a breach of these rules, and what the characters of these legal consequences are.

However, the number of connections between legal obligation rules aimed at private parties and non-legislative acts is significantly higher under MiFID II than under MiFIR. Indeed, of the total number of such connections under MiFID II, 64 per cent are to rules stipulating legal obligations on private parties. 


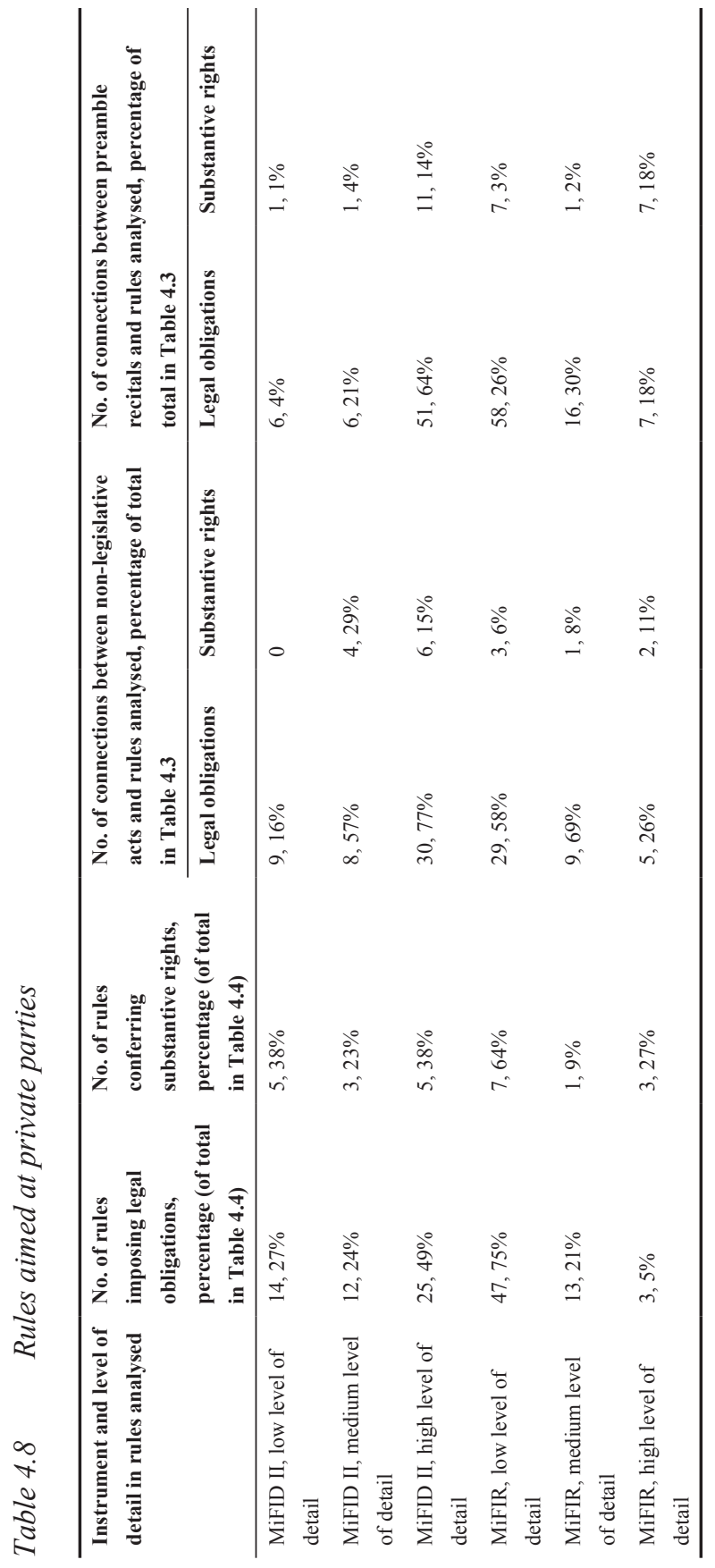


Some of these are related to the flow of information, as already mentioned, but a significant proportion of these connections are to Commission Delegated Regulation (EU) 2017/565, which specifies organisational requirements for investment firms. This serves to illustrate that the EU is capable of laying down detailed substantive obligations on private parties in non-legislative acts, which must be seen as a clear instance of centralisation.

As regards substantive rights for private parties, the numbers of such rules are small, which has a negative impact on the reliability of comparisons. If a difference can be discerned, it is to indicate that there are slightly more substantive rights rules with high regulatory intensity in MiFID II than in MiFIR, and these are to a slightly higher extent elaborated in preamble recitals.

To summarise, the seeming tendency to create legal obligations on private parties through MiFIR, a regulation, has been demonstrated to relate mostly to procedural matters related to the communication of information, while substantive obligations are generally in MiFID II. It further follows from the study that such substantive obligations can be elaborated in non-legislative acts and it has been submitted that this includes centralisation of rulemaking power to the EU institutions (mainly to the Commission). This raises questions on the specific character and the constitutional legitimacy of these elaborations that deserve further attention.

\subsection{CONCLUSIONS}

This study has been a quantitative comparison of MiFID II and MiFIR, endeavouring to approximate the level of centralisation of financial market governance in the EU. This has been done by measuring regulatory intensity in the two instruments, including their connections to delegated and implementing instruments. To operationalise the comparison, the rules in the instruments were coded so as to differentiate between four classes of regulatory addressees: EU institutions, EU agencies, Member State actors and private parties. Furthermore, the characters of rules were distinguished into the categories of legal obligations, discretionary powers and substantive rights.

At a general level, it has been possible to conclude that there is no significant difference in regulatory intensity between MiFID II and MiFIR. This falsifies, for the purposes of this limited sample, the expectation that a regulation will necessarily include a higher regulatory intensity - and thereby a higher level of centralisation of normative power to the EU level - than a directive. This conclusion led the inquiry on to an examination of regulatory intensity in the respective instruments with respect to the regulatory addressees involved. These were categorised as EU institutions and agencies, Member State actors, and private parties. 
It has been possible to conclude from this study that there are more rules stipulating legal obligations on EU institutions in MiFIR than there are in MiFID II, and more rules governing EU agencies in MiFIR than in MiFID II. It has also been demonstrated that the regulatory intensity in rules conferring discretionary powers on EU agencies is higher in MiFIR than in MiFID II. Other comparisons of rules aimed at the EU institutions or agencies were inconclusive. These results do, however, strengthen the expectation that the EU legislator will address EU institutions and agencies in regulations rather than in directives. The study has also allowed the hypothesis that the EU legislator has wished to control EU agencies' use of temporary intervention powers in the financial markets.

As regards rules addressing Member State actors, it has been demonstrated that legal obligations of Member State actors are stipulated in MiFID II rather than in MiFIR. This is in line with the expectation that the EU legislator will use directives rather than regulations to govern national activities. It has further been demonstrated that there are more legal obligations on private parties in MiFIR than in MiFID II, but that the characters of the rules are different. Substantive obligations on private parties are generally stipulated in MiFID II, reinforcing the expectation that the EU legislator legitimises such obligations through Member State legislation transposing EU rules into national law. These results also seem to suggest that the introduction of MiFIR to accompany MiFID II was primarily triggered by the need to govern institutional interaction between the EU institutions and agencies (mainly the Commission and the ESMA).

Interestingly, however, a tendency has been discerned for the activities of national authorities to be governed to some extent through non-legislative acts and through preamble recitals. This means that the EU legislator has seemingly wished to create possibilities for the EU institutions (and agencies) to partially pre-empt the margins of discretion that national authorities enjoy under the rules of MiFID II and MiFIR, and that this opportunity has been used to some extent. This also applies to legal obligations on private parties. It has also been highlighted that the balance in the conferral of discretionary powers is to the benefit of EU institutions in both instruments, suggesting a clear element of centralisation, and that most of these discretionary powers are given to the Commission in order for it to be able to adopt non-legislative acts. It can therefore be concluded that there is a discrepancy between the main instruments MiFID II and MiFIR (which mainly follow the expected pattern of using directives to be transposed into national law by national legislation for the governance of national authorities and private parties) and centralised EU rulemaking through non-legislative acts (which are almost exclusively regulations but will nevertheless have an impact on the rights and obligations of national authorities and private parties). It should be recalled that non-legislative acts are neither 
subject to Parliament or Council approval nor to the procedure for national parliamentary review of new EU acts under Protocol (No 2) on the Application of the Principles of Subsidiarity and Proportionality. Consequently, many veto players, or rather veto functions (checks and balances), in rulemaking are by-passed in non-legislative rulemaking. As mentioned above, this is likely to increase centralisation, and furthermore it triggers constitutional tensions (van Cleynenbreugel 2014; Bergström 2015; Chamon 2016) that may surface in legal discourse on financial market rules.

In sum, it has been demonstrated that MiFID II and MiFIR, and the non-legislative acts adopted on the basis of them, constitute an extensive set of rules centralising the system of trade in financial instruments in the EU. At a general level, the choice of a regulation or a directive did not in this case seem to have any significant impact on the level of centralisation achieved through the instrument. Instead, the rules in the respective instruments seem to address different agents. In this respect, the choice of instrument meets expectations in the sense that MiFIR mainly governs the EU level of administration and MiFID II mainly governs the national level of administration and the rights and obligations of private parties. However, it has been further demonstrated that the activities of national authorities are also governed through the adoption of non-legislative acts that are, with few exceptions, regulations. This means powers conferred on the EU institutions under MiFID II and MiFIR entail a possibility of pre-emption of Member State discretion, which must be described as at least potential centralisation, and furthermore, as we have seen, the Commission has used this possibility extensively, which must be described as real centralisation. With regard to MiFID II and MiFIR, the common preconceptions concerning the respective characters of regulations and directives have thus not been falsified, but the study has consequently indicated that the use of a directive to govern national administrations and private parties may conceal the fact that they are to a large extent governed through non-legislative acts in the form of regulations. This form of normative governance through non-legislative acts is perhaps the most conspicuous aspect of EU centralisation in the legal governance of the financial markets indicated in this study.

\section{NOTES}

1. The author would like to extend my thanks to the entire team of colleagues involved in this book, and in particular to Heikki Marjosola, Adrienne Héritier and Magnus G. Schoeller. Thanks also go to Professor Daniel Mertens, University of Osnabrück, and to Professor Carl Fredrik Bergström, Associate Professor Malou Larsson Klevhill and Dr Rebecca Söderström, all at Uppsala University. They have all offered very valuable comments on earlier drafts of this contribution. Of course, any flaws in this text are my own responsibility. 
2. The study of the content and meaning of the law in any given field consists in the interpretation of texts and the interrelationship of these texts, and only that, while empirical study of, for instance, what people actually do is entirely irrelevant to the normative content of law. One might see this as an instance of 'Hume's law' (Hume 1739 [1896]: 469-470) insofar as empirical studies deal with what is or is not, while traditional legal studies deal with what one ought or ought not to do.

3. The EU institutions and agencies also issue soft-law documents that are not legal acts within the meaning of Art 288 TFEU, notably (in this context) the 'Guidelines' issued by the ESMA. These fall outside the scope of this study.

4. Bergström 2015, at 236, phrases this third criterion more broadly, saying that the delegation of powers is motivated by special needs.

5. Indeed, the interest of centralising certain aspects of the governance of trade in financial instruments, while allowing more flexibility for the Member States in other respects, is the reason put forth by the Commission in its considerations on the choice of legal instrument to be used. See Commission Staff Working Paper, Impact Assessment, SEC (2011) 1226 final (Brussels 20 October 2011): 59-61.

\section{BIBLIOGRAPHY}

Abbott, Kenneth W., Levi-Faur, David and Snidal, Duncan. 2017. Introducing regulatory intermediaries. The ANNALS of the American Academy of Political and Social Science 670 (1): 6-13.

Baldwin, Robert. 1996. Regulatory legitimacy in the European context: the British Health and Safety Executive, in Majone, Giandomenico (ed.), Regulating Europe. London and New York: Routledge, 83-105.

Bergström, Carl Fredrik. 2005. Comitology: Delegation of Powers in the European Union and the Committee System. Oxford: Oxford University Press.

Bergström, Carl Fredrik. 2015. Shaping the new system for delegation of powers to EU agencies: United Kingdom v. European Parliament and Council (Short selling). Common Market Law Review 52 (1): 219-242.

Bergström, Carl Fredrik and Ruotsi, Mikael. 2018. Grundlag $i$ gungning? En ESO-rapport om EU och den svenska offentlighetsprincipen. Swedish Ministry of Finance report: Rapport till Expertgruppen för studier i offentlig ekonomi, 2018:1.

Chamon, Merijn. 2016. EU Agencies: Legal and Political Limits to the Transformation of the EU Administration. Oxford: Oxford Studies in European Law, Oxford University Press.

de Larosière, Jacques (chair). 2009. The High-Level Group on Financial Supervision in the EU: Report. https://ec.europa.eu/economy_finance/publications/pages/ publication14527_en.pdf. Last accessed 25 March 2020.

Hume, David. 1739 [1896]. A Treatise of Human Nature. London: John Noon.

Lenaerts, Koen. 1993. Regulating the regulatory process: "delegation of powers" in the European Community. European Law Review 18 (1): 23-49.

Schammo, Pierre. 2011. The European Securities and Markets Authority: lifting the veil on the allocation of powers. Common Market Law Review 48 (6): 1879-1913.

SOU 2009:71 (Swedish Government Official Report 2009:71). EU, Sverige och den inre marknaden - En översyn av horisontella bestämmelser inom varu- och tjänsteområdet. Stockholm: Fritzes. 
van Cleynenbreugel, Pieter. 2014. Meroni Circumvented? Article 114 TFEU and EU

Regulatory Agencies. Maastricht Journal of European and Comparative Law 21 (1): 64-88. 